\title{
Article
}

\section{Working back to the future: strengthening radical social work with children and young people and their perspectives on resilience, capabilities and overcoming adversity}

Larkins, Cath, Satchwell, Candice, Davidge, Gail, Carter, Bernie and Crook, Deborah

Available at http://clok.uclan.ac.uk/35188/

Larkins, Cath ORCID: 0000-0003-2999-6916, Satchwell, Candice ORCID: 00000001-8111-818X, Davidge, Gail ORCID: 0000-0002-8241-3428, Carter, Bernie and Crook, Deborah ORCID: 0000-0003-1852-1130 (2021) Working back to the future: strengthening radical social work with children and young people and their perspectives on resilience, capabilities and overcoming adversity. Critical and Radical Social Work, 9 (2). pp. 185-204. ISSN 2049-8608

It is advisable to refer to the publisher's version if you intend to cite from the work. http://dx.doi.org/10.1332/204986020X16031172027478

For more information about UCLan's research in this area go to http://www.uclan.ac.uk/researchgroups/ and search for <name of research Group>.

For information about Research generally at UCLan please go to http://www.uclan.ac.uk/research/

All outputs in CLoK are protected by Intellectual Property Rights law, including Copyright law. Copyright, IPR and Moral Rights for the works on this site are retained by the individual authors and/or other copyright owners. Terms and conditions for use of this material are defined in the policies page. 


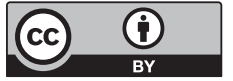

Accepted for publication 19 October 2020 • First published online 16 November 2020 This article is distributed under the terms of the Creative Commons Attribution

4.0 license (http://creativecommons.org/licenses/by/4.0/) which permits adaptation, alteration, reproduction and distribution for non-commercial use, without further permission provided the original work is attributed. The derivative works do not need to be licensed on the same terms.

\title{
article
}

\section{Working back to the future: strengthening radical social work with children and young people, and their perspectives on resilience, capabilities and overcoming adversity}

\author{
Cath Larkins, clarkins@uclan.ac.uk \\ Candice Satchwell, CSatchwell@uclan.ac.uk \\ University of Central Lancashire, UK \\ Gail Davidge, gail.davidge@manchester.ac.uk \\ University of Manchester, UK \\ Bernie Carter, Bernie.Carter@edgehill.ac.uk \\ Edgehill University, UK

\section{Deborah Crook, DCrook5@uclan.ac.uk} \\ University of Central Lancashire, UK
}

\begin{abstract}
Using data from participatory storytelling research with 65 young people, this article provides a co-created theoretical grounding for radical social work with children and young people. The problems and solutions social work should be seeking are explored in the light of resilience theories and the capability approach. The young people's perspectives echo but extend existing resilience interventions and definitions of the capability approach, highlighting structural and historical patterns of inequality. They call for a collective response to adverse experiences, which become obvious in one zone of experience but have consequences and roots in other places. Social work could usefully employ expanded understandings of socio-ecological resilience and the capability approach to focus interventions more clearly on the root causes of adversities and shape interventions that highlight capability sustainability and co-created solutions. This would involve professionals working alongside children and young people, as well as their families and allies, to confront enduring patterns of disadvantage.
\end{abstract}

Key words children in need $\cdot$ resilience $\cdot$ capability approach $\cdot$ child participation $\cdot$ social theory

To cite this article: Larkins, C., Satchwell, C., Davidge, G., Carter, B. and Crook, D. (2020) Working back to the future: strengthening radical social work with children and young people, and their perspectives on resilience, capabilities and overcoming adversity, Critical and Radical Social Work, vol xx, no xx, 1-20, DOI: 10.1332/204986020X16031172027478 


\section{Introduction}

The pursuit of change for children through social work is highly charged. Social workers experience political and media scrutiny, and this affects perceptions of which children are exposed to what risks and which responses are appropriate (Parton, 2014). Government rhetoric, supported by media coverage, presents social problems as caused by personal deficits (dysfunctional behaviour) and blames individuals for consequent national debt caused by demands on welfare systems (Garrett, 2014). Over the past 50 years, dominant narratives about child protection social work have shifted away from compassion for families in difficulty towards holding parents responsible, focusing on the internal working of individuals' brains or family dynamics (Featherstone et al, 2018). These factors combine to hide the underlying and systematic impact of deprivation and poverty on the life chances of children and parents (Featherstone et al, 2018). In sharp contrast, this article learns from children and young people's own stories of the challenges they have encountered, and sets out a new approach to identifying and addressing underlying causes.

In this Arts and Humanities Research Council-funded participatory story-focused research, children and young people's narratives of challenges and change resonated with but also extended two approaches to social work and child well-being that are widespread in international development discourses and social work practice: resilience (van Breda, 2018) and the capability approach (CA) (Stoecklin and Bonvin, 2014). Drawing perspectives from medicine and psychology into social work, resilience theory identifies factors that can be built into child and family interventions to enable individuals to bounce back from hardship (Zolkoski and Bullock, 2012). Drawing on economics, philosophy and development studies, CA focuses on capabilities that individuals need to live a good life and how these can be secured (Sen, 1999). Our data indicate the need for a greater focus on identifying causes, rather than symptoms, and for addressing both historical and contemporary adversity through co-created collective action.

In this article, we introduce literature on childhood, resilience and CA, and describe the methodology, the intergenerational research team and the participants. We present an overview of our findings, illustrating how analysis informed by an understanding of socio-ecological zones, time, CA and collective action can guide radical social work with children and young people. Finally, we discuss implications for theory and practice.

\section{Resilience, CA and social work}

Resilience tends to be defined within social work discourse as 'successful adaptation despite traumatic life events and/or a life course marred by chronic adversity' (Zabern and Bouteyre, 2018:324). The traumatic life events and chronic adversity from which resilient children can bounce back include poor health, family poverty, conflict, maltreatment, violence, abuse, neglect and experience of discrimination (Zolkoski and Bullock, 2012), as well as living in communities experiencing poverty, crime and family troubles (van Breda, 2018).

A systematic review of literature on resilience-promoting factors for children in out-of-home care revealed that individual factors are emphasised (Zabern and Bouteyre, 2018). Of the 100 protective factors identified in their review, 44 referred 
to children's individual characteristics, ten to family of origin, 29 to professionals, eight to sources of external support and nine to context. The focus on individual and family factors is also seen in Zolkoski and Bullock's (2012) review of child and youth resilience literature from the 1970s onwards. Combined, these articles suggest that: individual resilience-promoting factors include emotional regulation, confidence, self-esteem, self-efficacy, empathy, the capacity to take positive action, insight, perseverance, hope and desire to break negative patterns; and family factors include responsive and supportive parenting styles, the presence of positive caregiving, family cohesion, stimulating environments, social support, and adequate income. Resilience interventions consequently tend to focus on training and experiences for children (to develop social and emotional capacities or build peer relationships), promoting parenting skills, or providing opportunities for positive parent-child interactions.

Some literature acknowledges that community factors also promote resilience but the influence of political and economic dynamics is largely underplayed. Community factors include the presence of welfare and leisure services, social support, and supportive professionals (Zolkoski and Bullock, 2012). These community factors are encouraged when services are long-established, coordinated and evidence-based (Ungar et al, 2014), by bringing services into accessible community spaces, like schools (Zolkoski and Bullock, 2012), and by encouraging peer support between families (Piel et al, 2017).

While a focus on resilience is welcomed by some as a strengths-based approach that recognises children's agency (Titterton and Taylor, 2018), there are major critiques of the concept. Neocleous (2013: 7, quoted in Garrett, 2015: 12) notes that resilience demands 'acquiescence, not resistance'. Resilience talk also normalises adversity as the emphasis is laid on the need for individuals to adapt rather than for adversity to be stopped (Garrett, 2015). Hart et al's (2016) review of literature critiquing resilience shows that unless there is clear understanding of the interplay between agency and structure, resilience talk may depoliticise, diverting attention away from structures and states. Normalising and depoliticising adversity creates a climate in which relying on children's resilience to overcome adversity is acceptable as children will or should cope.

To retain attention to politics and structures, Daniel and Wassell (2002), Ungar (2011), Hart et al (2016), Titterton and Taylor (2018) and others argue that resilience should be understood in socio-ecological context, which can then guide social work interventions across what van Breda (2018: 2-3) calls the 'micro-meso-macro continuum'. For example, Daniel and Wassell (2002) propose a socio-ecological framework of six domains (secure base, education, friendships, talents and interests, positive values, and social competencies), which spread across individual, family and community zones of experience. Similarly, Ungar (2011: 6) challenges the responsibilisation of families, stating the need to 'shift from changing individuals to making social and physical ecologies facilitative'. Also, Hart et al (2016) argue that resilience interventions must attend to social and economic conditions that disadvantage individuals and communities, and suggest the need for co-designed social justice-oriented resilience interventions that transform adversity.

While a socio-ecological approach to resilience does push the focus towards contextual factors, a mindset of focus on individual change still remains in some of these practice models and the need for creative alternatives is acknowledged. For example, Titterton and Taylor's (2018) life-course model emphasises the individual's 'resourcefulness' and provides little detail about how individuals interact with systems 
and structural factors. Piel et al (2017) describe the need for cultural change to reduce macro-level stigma related to care experience, yet their recommendations for practice change focus on micro- and meso-level contexts. Titterton and Taylor (2018) acknowledge that more creative thinking is needed, and Aranda and Hart, (2015:13) propose that professionals should experiment in achieving changes by using available networks and assemblages of activities and resources.

However, even the more radical socio-ecological versions of resilience thinking suffer from what can be termed 'flat ontology' (Donati, 2016), which lacks understanding of the entrenched nature of disadvantage. While radical socio-ecological resilience may see the world as composed of 'complex ... unpredictable messiness ... [and] emergent enactments' (Aranda and Hart, 2015: 13-14) and acknowledge the need to focus on discrimination, socio-ecological models that focus on unpredictable messy practice may fail to recognise the temporal dimension of how predictable structured patterns of disadvantage are created by past actions, not just enactments in current contexts (Donati, 2016). Joseph (2016: 379) suggests the consequence of this ontological contingency is that resilience thinking tends towards attempting small adjustments in practices rather than large-scale change. The task for radical social work with children, then, becomes to enable social work practice to create social change. For example, there is need for more practice tools to help disrupt the highly predictable and enduring disadvantaged patterns of social relations that increase the likelihood of social work intervention (Morris et al, 2017).

CA is proposed as a tool for enabling social work to avoid responsibilising individuals and to seek social change (Gupta et al, 2016). CA (Sen, 1999, 2005; Nussbaum, 2011) argues that individuals' capabilities (opportunities to be able to attain things that they value) are related to both means (income and goods) and conversion factors (personal, political, social, economic and environmental conditions that enable or constrain individuals' capacity to transform means into things they value). Nussbaum (2011) describes these valued achievements as functionings. To achieve equality of functioning, and overcome constraints in conversion factors, social work may need to recognise that some people require more opportunities and resources than others (Carpenter, 2009: 356), and to address structural inequalities related to, for example, class, race, disability and gender (Carpenter, 2009), social constructions of stigma (Roose et al, 2014), and 'the discourse of individual pathology and blame' (Gupta et al, 2016: 364). CA can provide a framework for reviewing social work practice because it reveals structural processes and power relationships, as well as proposing strategies for increasing individual agency (Raemdonck and Seedat-Khan, 2018). For example, CA provides a framework for assessing how functionings are affected by severe poverty (Skattebol and Redmond, 2019) and a discourse that frames a lack of valued resources as an opportunity for growth rather than as a social injustice (Fattore and Fetger, 2019).

In contrast to resilience, CA may provide social work with an approach aligned to insights from childhood studies (Stoecklin and Bonvin, 2014). Although resilience is strengths-based and recognises children's agency (Titterton and Taylor, 2018), adversity is seen to disrupt 'normal development' for future adults (Zolkoski and Bullock, 2012); however, judgements about 'normal development' and appropriate outcomes are culturally specific and value-laden (Garrett, 2015). CA focuses on the present experiences and life goals of children rather than future outcomes (del Moral-Espin et al,2017). Resilience research has not adequately engaged with children and young people's perspectives, and tends to be measured through surveys (Hart et al, 2016). CA 
Table 1: Social work contact and criteria described

\begin{tabular}{|l|l|c|}
\hline \multicolumn{2}{|c|}{} & $\begin{array}{c}\text { Numbers of } \\
\text { interviewees }\end{array}$ \\
\hline \multirow{3}{*}{$\begin{array}{l}\text { Contact and } \\
\text { criteria }\end{array}$} & Only assessment named & 3 \\
\cline { 2 - 3 } & Care experience & 12 \\
\cline { 2 - 3 } & Receiving disability-related support (independent living) & $10(5)$ \\
\cline { 2 - 3 } & Young carer & 8 \\
\hline
\end{tabular}

can provide a role for vital public debate as regards relevant capabilities (Sen, 2009), including with children (Biggeri et al, 2006; del Moral-Espin et al, 2017). However, Dean (2009) cautions that CA can focus attention on individual agency and obscure social drivers because CA concepts are inherently liberal; agencies may adopt capabilities discourses while ignoring the causes of inequality, and the scope of public debate about relevant capabilities is constrained by hegemonic control over public reasoning. Practice tools that aim to disrupt enduring patterns of disadvantage through CA must therefore have a strong focus on social contexts and conversion factors.

\section{Methodology}

Our approach contrasts with previous attempts to explore resilience and capabilities, responding to the call for opportunities for people who use services to tell their own stories (Featherstone et al, 2018). Working with 12 young researchers, in an approach based on the belief they had much to teach academics, as well as there being much for us to learn together (Brownlie, 2009), our intergenerational research team created opportunities to experiment with methods for sharing stories and for keeping each other safe in this process (Dan et al, 2019). We co-created participant information, a recruitment strategy and an interview guide that offered opportunities to play, create artistic representations with colours and collage, or act out scenes. Rather than employing abstract terms or asking about an abstract child (Biggeri et al, 2006: 69; del Moral-Espin et al, 2017:209), the narrative interview guide invited interviewees to tell stories about their life challenges or disadvantages, hopes, and highlights, as well as how they overcome difficulties and achieve goals. The word 'challenge' was understood by the young researchers as specific events and circumstances that were experienced as difficulties. 'Disadvantages' were longer-term and not always vocalised by the young people themselves.

Ethical approval was given by the University of Central Lancashire Ethics Committee. Before the taking part (as young researchers or as interviewees), accessible information about the study was discussed with all participants. They signed their consent, and parental consent was also secured for under-16s. Strategies for protecting confidentiality and dealing with upsetting stories were regularly reviewed through research team discussions. For example, young researchers, who conducted over half of the interviews in the study, were always accompanied by experienced academics (the authors) and this enabled them to ask for our support at any moment.

In total, 85 interviews were conducted in Northern England with 65 children and young people aged 10-25 years (44 were aged 16-19). A total of 15 young people requested opportunities to take part in second or, in some cases, third interviews as they had more stories they wanted to tell. Of the interviewees: 28 were female and 
37 were male; nearly a quarter were of minority ethnic heritage (South Asian and Traveller), reflecting the diversity of the study area; and 36 were disabled. All were accessing services (social services, education settings, youth clubs or participation groups) and met a variety of referral assessment and intervention criteria for contact with social services (see Table 1).

Analysis of the data was multilayered. Line-by-line analysis of patterns within transcriptions was conducted (Fraser, 2004). Adult and young researchers familiarised themselves with the data using the question: 'What strikes me?' (Satchwell et al, 2020). Adopting the ecological approach of expanded resilience theory and CA, three adult researchers used Bronfenbrenner's (1994) model of zones of experience as a heuristic tool to explore how the challenges and supportive factors spread across internal processes (feelings, thoughts and behaviours), proximal zones (family, friends and where they live), meso-level processes of services (schooling, welfare and outreach services) and macro-zone economic and cultural inequalities (discrimination and poverty). Learning from Oliver's (2012) guide to critical realist social work research, we sought causal explanations of patterns of disadvantage, acknowledging the different temporal phases through which agency (in time 1), affects the structured contexts experienced (in times 2-3), which are, in turn, maintained or transformed (in time 4). As shown in Figure 1, analysis therefore worked backwards from interviews with children and young people's perspectives on their current (time 3) and recent (time 2) experiences to identify underlying and often unnamed conditions that were antecedent adversities (time 1) that potentially caused the recent and current contexts of the experiences they described and might affect the future contexts in which they would try to achieve goals (time 4). We describe this ontologically deeper form of analysis as working back to the future.

Emerging analysis was discussed and refined with young researchers through creative methods (Larkins, 2019). Fictionalised short stories based on the data were also co-created with the young researchers, creative writers and filmmakers, drawing together the key insights and events from the interviews but communicating these in ways that protect identities (as described in Dan et al, 2019). In this article, we provide

Figure 1: Working back to the future to understand historical contexts

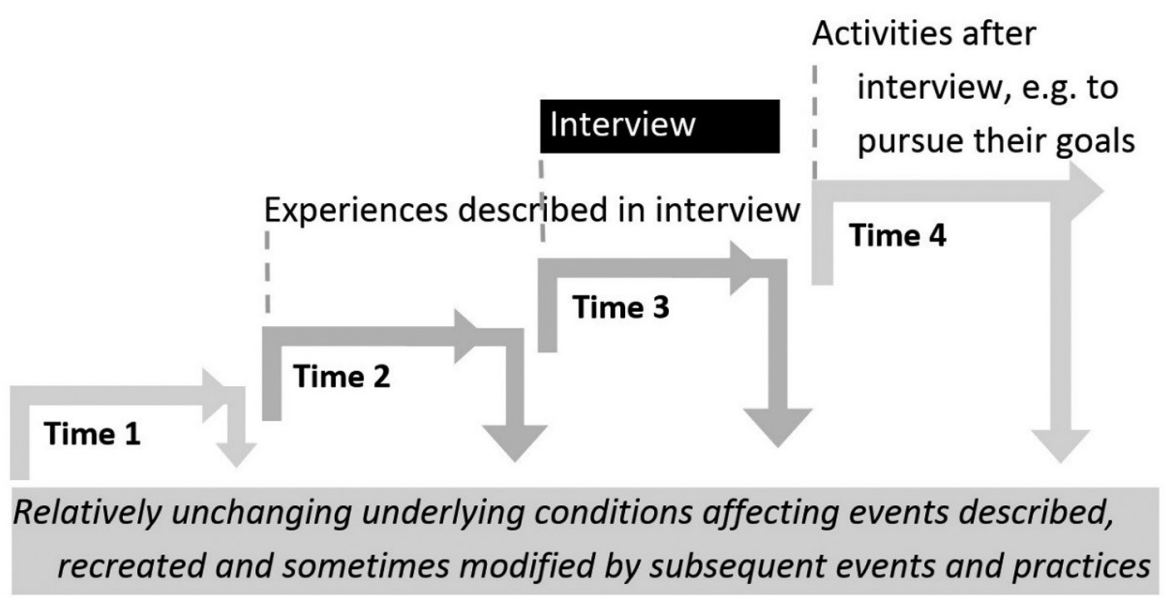


links to examples of these rich and emotional engaging accounts that connect to the summary data presented. Pseudonyms are used throughout.

\section{Findings}

The 65 interviewees recounted goals and achievements that, combined, can be described in CA terms as the following capabilities or functionings: health; feeling positive and valued; positive social relationships; feeling safe and settled; home; employment; financial security; staying out of trouble; making a difference; leisure activities; independence (including travel); education and skills; no discrimination; and respect. As shown in Table 2, the findings broaden current UK (Burchardt and Vizard, 2011) understandings of children and young people's valued capabilities and functionings to include new domains (staying out of trouble, independence, no discrimination and employment), as well as to deepen understanding of home as a safe and settled place that may be away from family. This study also expands international capability lists created with children (Biggeri et al, 2006; del Moral-Espin et al, 2017) by suggesting that the notion of staying out of trouble should be linked with financial security, and that the term 'participation' might be replaced with 'making a difference' (as interviewees underlined that collective voice and related actions should have positive social consequences).

The concerns of resilience theory when it has an ecological or social justice orientation are also evident in the interviews. In line with Daniel and Wassell's (2002) six domains, friends were described as "a tight circle", who "trust, accept and look out for each other" and who could "calm you down, help you chill out" and "have a laugh together". However, in contrast to Daniel and Wassell (2002), the interviewees in our study stressed the importance of opportunities to make a difference to the world and the need to feel valued (rather than to demonstrate pro-social values).

As Dean (2009) notes, there is need to contextualise expanded understandings of relevant capabilities in understanding the causes of inequalities and a range of different circumstances that act as barriers. The interviewees named challenges and disadvantages related to emotions, education, friendships, families and relationships, health, discrimination, age-based transitions, living arrangements, employment, leisure activities, community, poverty, and getting into trouble. For example, one young woman described domestic violence: "[Mum] had this boyfriend ... an absolute dickhead, I cannot find a better word for him ... he used to, like, knock her about, which [deep breath] he justified and my sister justified by saying 'She provokes people'.' These challenges, described in detail in some of the young researchers' fictionalised stories (available at: www.stories2connect.org), included: six of Felitti et al's (1998) forms of adverse childhood experiences (experiencing abuse, witnessing domestic violence or living with family members who are substance abusers, mentally ill, suicidal or imprisoned); all of Titterton and Taylor's (2018: 1550) major life events; Hart et al's (2016) notion of disadvantaged communities; and Daniel's (2010:232) conception of adversity, which includes 'structural inequalities and socio-economic disadvantages'.

The challenges that interviewees described cut across internal, proximal, meso and macro zones of experience, where recent and current challenges related to emotions or relationships were linked to social inequality (related to gender, generation, disability, class and racism), lack of services and employment opportunities, poverty, 


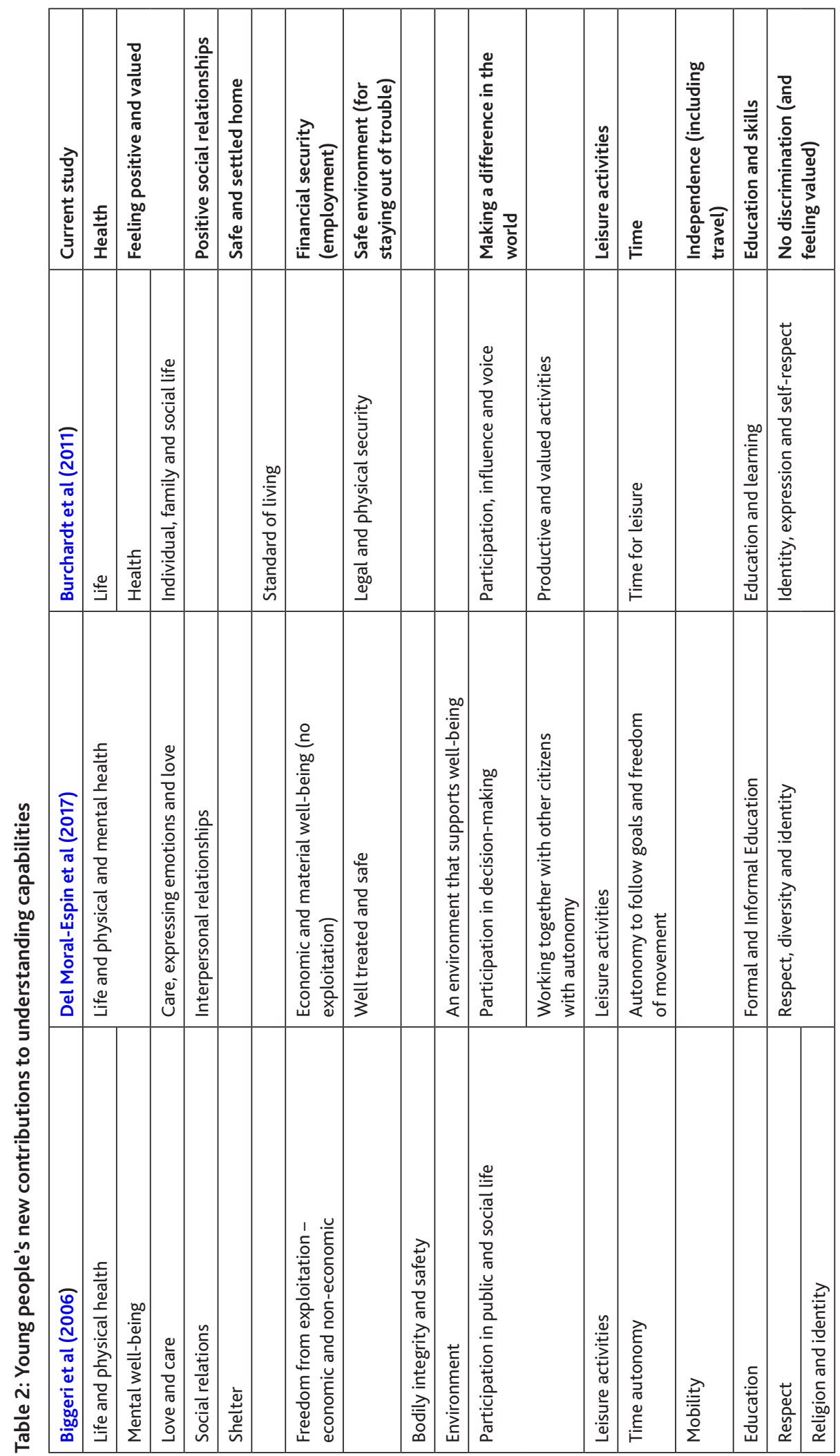


Figure 2: Childhood adversities seen across zones and across time

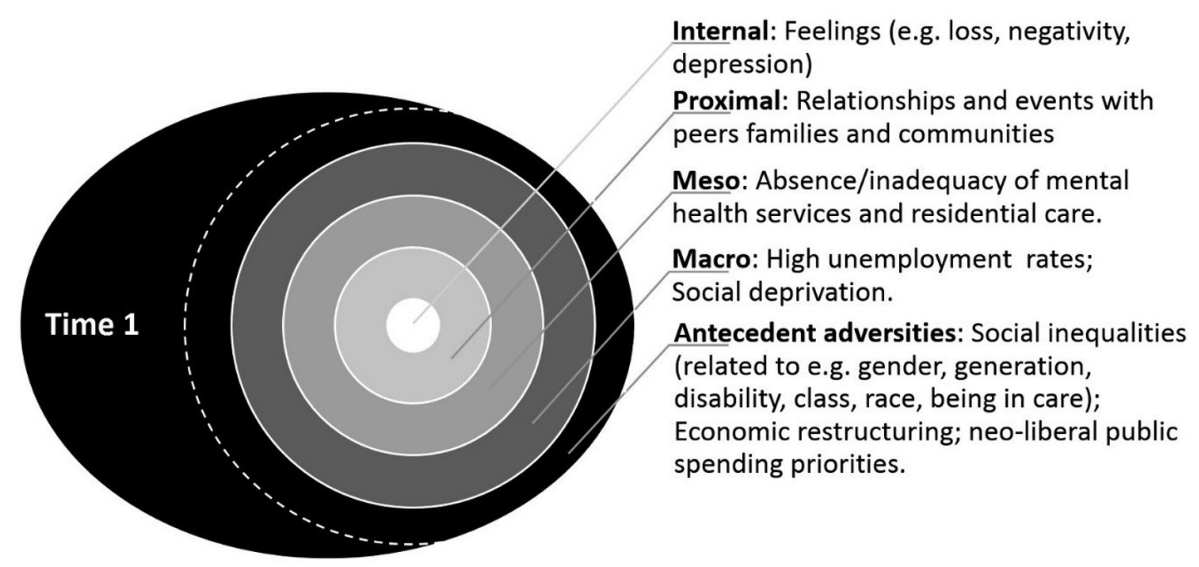

and economic restructuring and austerity politics. For example, one young man described his fear related to experiences of racism:

\begin{abstract}
'being, like, a Traveller and that it's looked down on ... one night I just like felt like I couldn't go to sleep because I thought they [other local residents] was going to come in ... someone tried to run us over ... they tried to wind us up ... so we get in trouble.' (Sean, aged 12)
\end{abstract}

In the following subsections, we therefore unpick the ways in which challenges spread across internal, proximal, meso and macro zones using Oliver's (2012) critical realist approach to understanding antecedent causes. We then explore how a CA focus on conversion factors, as well as capability sustainability and 'making a difference' activities, might provide a fuller grounding for radical social work with children and young people.

\title{
Adversities set in antecedent contexts
}

As summarised in Figure 2, our findings suggest that the challenges interviewees experienced, which cross internal, proximal, meso and macro zones, are related to antecedent adversities that have their roots in time 1 but that continue to structure the contexts of the events described in the interviews. This is illustrated using three examples: experiences of childhood abuse and parental mental health; staying out of trouble and getting into work; and transitions through the alternative care system.

In a first example, Sarah described the absence of effective social work intervention and the emotional consequences of witnessing domestic violence and significant caring responsibilities: "having to put a front on to the rest of the world ... every single day was just a battle.... I was experiencing all these emotions ... when I was 12, I found out [through self-diagnosis on the Internet] that I was going through depression" (Sarah, aged 16). She recounted internal impacts of domestic violence on her own and her mother's mental health, the meso-zone lack of mental health service provision, and the consequent difficult circumstances in which she sought to 
thrive in education and friendship groups (see: http://stories2connect.org/stories/ you-can-do-anything/).

Working back in time, potential antecedent macro roots of the challenges that Sarah described in her interview are suggested in other research that shows the link between DV and the performance of heteronormative male controlling behaviour and patterns of labour exploitation (Fraser et al,2018). Therefore, the recent and current (times 2-3) experiences that Sarah described were in the context of antecedent (time 1) inequalities in gender relations and public spending decisions regarding mental health service provision. These antecedent adversities affected the internal, proximal and meso contexts in which Sarah and her mother tried to develop feelings of being valued and to access mental health support.

Taking a second example, recent challenges of staying out of trouble and getting a job were described in a conversation between three young men (aged 17-20):

Basim: 'When my grandma passed away ... it felt like what is the point, like, bothering anymore?... it was like a massive void ... getting up to stupid things, it kind of distracted me from that. I was getting involved in drugs. I was always getting in trouble with the police.'

Tafari: 'Where I live ... it's not a good group. They're, like, a bad influence.... My challenge is staying out of trouble.'

Pasir: 'Every day. Every day's a challenge....You get some people, like one out of every hundred that manage to get out ... they've moved out wherever and they're in nice house, family and car, whatever. So, that is possible.'

Basim: 'I don't want my kid going through what I went through. I want to live in a cul-de-sac in a good area. Here, you walk to the shop, you come back and on the way ... there's a fight going on. Someone will be drinking, they're pretty much all drunk ... it's a close community and that.... But it's just not very positive because not many people are doing well.'

Pasir: 'It's going to be very difficult to change that if people have been not doing well for the last 25 years, last 30 years, 40 years.'

These are proximal, meso and macro challenges related to personal loss, peer groups and the difficulties associated with living in a deprived area.

These challenges in relationships and places where they live were experienced in the context of recent (time 2) and current (time 3) economic disadvantages and racism. The community they describe has been one of the most socially deprived urban wards in the country since at least 1971 (Norman, 2016). Other interviewees in the area said “jobs are like hens' teeth", in that they are hard to find (see: http:// stories2connect.org/our-stories-2/jobs-are-like-hens-teeth/), and others mentioned racism as a barrier to education and employment (see: http://stories2connect.org/ stories/its-all-about-the-beard/ and http://stories2connect.org/category/stories/). The lack of employment opportunities and racism has historical roots (time 1) and can be traced back to the decline of the cotton industry and a fall in the UK's international competitive advantage from the mid-19th century until the 1960s (Mass and Lazonick, 1990). These antecedent adversities affect the recent (time 2), current (time 3) and future (time 4) contexts in which these young men were seeking to do well in education and employment. 
The third example concerns challenges associated with alternative care. Interviewees came into alternative care due to family adversities (particularly death of primary carers and substance abuse) but also disability discrimination. For example, Rob described his family as being "scared I'd set the kitchen on fire". He said people, including his family, should "not judge ... autism, because it's not fair". However, challenges continued within the care system, as he described:

'I had to leave [a children's home with really nice young people and staff] at $18 \ldots .$. I cried for, like, a few weeks.... There were people there that I'd known since age $15 \ldots$... [At the new place,] things were hard, [I felt] anxious for meeting new people ... some other tenants ... weren't very nice ... and used to attack me.' (Rob, aged 23)

Rob and other care-experienced interviewees described recent and current (times 2-3) emotional challenges arising from disrupted relationships with families and carers. They identified proximal challenges in relationships with peers, including bullying in peer relationships related to social stigma about alternative care (see: http://stories2connect.org/young-people/key/).

Working back in time from Rob's description of moving from a children's home before he was ready and focusing on macro-zone contexts, a second antecedent pattern of disadvantage is evident, arising from generation-based policies regarding age-related transition within social care. In his new placement, he experienced violence and a challenging mix of tenants. This may be linked to recent (time 2) or past (time 1) priorities in political decision-making regarding spending on social care, transition planning, the deregulation of leaving care placements, a shortage of placements or the need to avoid leaving prepaid placement spaces empty. This political decisionmaking is a consequence of long-established (time 1) neoliberal economic agendas influencing the commodification of social care that are now normalised (Garrett, 2014) but that continue to cause disadvantage.

As identified in previous research (Featherstone et al, 2018), our findings confirm that the challenges that bring children to the attention of social services spread across the internal and macro zones. Our research also emphasises the way in which adversities spread across time as well. The implications for social work practice are addressed in the discussion section.

\section{Facilitators set in social contexts}

The interviewees achieved the capabilities and functionings they valued through personal capacities, supportive relationships, opportunities and activities rooted in internal, proximal, meso and macro zones, as well as in different points in time. In CA terms, these could be described as means (personal income and primary goods) and conversion factors (personal, political, social, economic and environmental conditions). The supportive personal attributes interviewees identified included feeling positive, having a positive attitude, managing stress and self-care, being able to communicate, and knowing lots of people. Positive relationships were with family, friends, pets or professionals who listened, respected and supported by providing emotional and practical help. These means and personal conversion factors were used by interviewees to pursue their goals. Friends, families or services provided access to sports, leisure and 
travel, youth groups, 'making a difference'/voice and social action activities, specialist support, education, work, and being part of a group. In CA terms, the availability of these activities can be seen as a conversion factor (the social conditions) that affects how far interviewees could convert their personal means into valued functionings. However, as illustrated later, wider political and economic conversion factors also affected functionings related to, for example, staying out of trouble, gaining employment and feeling safe and settled.

For example, the three young men introduced earlier described staying out of trouble (related to being well treated, feeling safe and financial security) through using personal means and conversion factors. In ways that echo resilience literature (Daniel, 2010), Pasir described personal capacities of self-reliance (means) and Tafari mentioned family and peer support (conversion factors):

'You've got to decide yourself. No one else is going to realise or they're not going to feel what you're going through.' (Pasir, aged 17)

'My family have got me off the wrong track.... I started learning books ... getting into college, staying off the streets, staying at home ... one of my friends ... basically, he just showed me that life could change.' (Tafari, aged 17)

Meso-zone positive professional relationships were also a social conversion factor that enabled Basim to reach out for additional support when needed:"my youth worker ... she always did take, like, the time out for us. Like, you could have rung her any time of the day ... she inspired me" (Basim, aged 20). Personal and social conversion factors were not, however, sufficient as they described "only one in four" of their peers getting out of trouble. The economic and political conversion factors of job opportunities and an end to racism may also be necessary, and a suitable focus for social work with young people on the edge of youth justice interventions (Wainwright and Larkins, 2020).

Challenges in gaining employment despite parental, peer and professional support were related to disability discrimination for some young people, as Max explained: "My dad's helped me to gain confidence and ... then some of my friends ... my social workers ... they like helped me a lot ... but I don't like people, how they stereotype about [impairment]" (Max, aged 22). Only 5.8 per cent of adults who, like Max, receive long-term local authority support with a primary reason of learning disability are in paid employment; in the study area, this fell to less than 2.5 per cent (ONS, 2017). This might be described as the absence of the necessary conversion factor of nondiscriminatory environments, which limited the effectiveness of personal means and conversion factors. The context of limited employment opportunities and widespread disability discrimination affected Max's job prospects. Rather than conventional social work, which seeks to increase personal means or individual and familial resilience factors, CA's focus on including social, political and economic conversion factors might help address the antecedent nature of some of the adversities the interviewees encountered.

Nussbaum's (2011) focus on capability security may also be useful as it emphasises the importance of sustaining capabilities over time through the creation of enduring conditions. For example, interviewees described social work assessments and interventions positively (being removed from situations of sexual abuse; provision of personal assistants; placements; negotiation of contact; and support in gaining employment) when they enabled them to securely achieve long-term functionings (improved family and family-type relationships; feelings of safety, happiness and 
independence; and access to leisure). Echoing Daniel's (2006) emphasis on the importance of a secure base, these stories (see: http://stories2connect.org/youngpeople/soundcheck/) highlight current risks to secure, long-term functionings that are posed by a reduction in funding to services. As one young woman described:

'It's like a little family.... Like, Adam is the dad and he cooks for us all and ... Jane, just like that auntie that everyone just laughs at.... I were more or less brought up in the youth club ... the youth workers were there to look after me. Every time I had a problem with my parents, Jane were there to talk to me 24-7. She was brilliant. But then, I just found out that this new, like, plan [for cuts] ... not going to have a youth club anymore ... it's really upsetting that, knowing that they're going to get rid of something that's, like, it's massive!' (Lottie, aged 16)

Lottie and others stressed how consistency in personnel made young people feel well known and able to talk about anything; this was reliant on long-term funding for services. In addition to focusing on the presence of personal means and capabilities, CA-inspired radical social work might also therefore focus on the security of conversion factors. This would necessitate addressing the antecedent root causes of cuts in services, including the neoliberal politics of austerity (Garrett, 2014).

\section{The potential of 'making a difference' interventions}

Interviewees repeatedly mentioned 'making a difference' activities. These involved interviewees running events, helping design, inspect or evaluate services, creating support groups in their communities, lobbying local and national government, and volunteering. More than any other intervention, they described how these activities could address antecedent adversities and improve sustainability of personal means and social conversion factors. These activities have parallels with Hart et al's (2016) conception of social justice-based resilience thinking, in that 'making a difference' enabled community-level changes, creating social relationships and co-designed services that benefit the individuals involved and wider populations. In CA terms, experiencing making a difference was a valued functioning; participating in 'making a difference' activities created personal means and conversion factors; and 'making a difference' activities could result in social environments that acted as social or political conversion factors for others. This is illustrated by three examples related to leaving care and transitions for disabled young people.

One care-experienced interviewee described a voice-based 'making a difference' activity. This included a group meeting with a corporate parenting board. Taking part provided him with positive feelings and skills, as he noted:

'this [name of research] project got me to be able to talk ... in front of lots of people and share stories with other people as well.... I've just started at college in September and I've met ... I made some new friends and I told them about my story and everything like that, so I think it's helped me to be more confident in talking about it.' (Harry, aged 14) 
Through a series of participation group meetings, and collaboration with other campaigners, Harry had also helped achieve a "care leavers Council Tax exemption for up to 25 year olds ... in a couple of councils", as he describes:

'I went [to the meeting] with a couple of participation workers and about ... six or seven care leavers ... we set things out ... a care leaver, she said that she couldn't really pay for anything ... she was really struggling ... the Council Tax was too much for her. So there was discussion ... and then we brought it back to the Corporate Parenting Board and that's pretty much it.' (Harry, aged 14)

A second example was related by Rob, who was described earlier as facing bullying and social stigma about alternative care, and a pattern of disadvantage arising from generation-based policies regarding age-related transition within social care services. He talked about helping to create a leisure club "for all like young people ... aged 8-30 years". This research study itself is a third example of a 'making a difference' activity cited by interviewees. Their hope, shared with the young researchers, was that retelling their stories in emotionally engaging and academically rigorous ways would challenge stigma and enable wide public understanding of the lives of children and young people who are disabled, care-experienced or living with other aspects of disadvantage.

All of these examples show the potential for making a difference to create environments that also promote means, conversion factors and functionings. For example, changes in tax liability may enable care leavers who have gained employment to achieve the functioning of financial security and stability at home. The leisure club for 8-30 year olds challenged some of the current (time 3) effects of structural disadvantage caused by generation-based transitions between services for disabled young people. Rob's hope was that this co-created leisure club would also challenge future (time 4) assumptions, rooted in time 1, that service transitions should occur at age 25 . The research study generated personal means and conversion factors (feeling valued, having positive social relationships, gaining skills and temporary experiences of non-discrimination) and our attempts to challenge structural disadvantage are ongoing.

\section{Discussion}

This study is limited in that it engaged with children and young people in only one region of England. However, it was initiated by and included a wide range of participants who had personal and social characteristics that make them targets for social work assessment and interventions. The study therefore provides a unique contribution to the small international field of research with children and young people on their perspectives on resilience and capabilities. There remains a need for further studies to include other children that were not targeted as part of our study, for example, those aged under ten, asylum seekers and those in other countries.

Our findings show that whether analysed through the lens of socio-ecological resilience or CA, there is considerable consensus on the difficulties that children and young people experience, the goals they define, and the factors that facilitate achievement of these goals. Difficulties related to individual, family, community and environmental factors, some of which were relatively long-standing (social 
inequality related to gender, generation, disability, class and racism; lack of services and employment opportunities; poverty; and economic restructuring and austerity politics). Echoing existing critical social work literature (Stevens et al, 2019), there is a need to focus on socio-ecological factors and to guarantee social provision in order to challenge deep-rooted inequalities.

Our study adds a temporal understanding by applying ecological social justice-based resilience and CA theory, drawing attention to the antecedent and causal impacts of relatively stable patterns of disadvantage. Challenges, disadvantages and conditions (supportive or limiting conversion factors) spread across a social ecology of zones of experience but their historical roots are rarely acknowledged. We have proposed the term 'antecedent adversities' in order to invite practices that think back in time from experiences described in interviews to identify the influence of long-established patterns of disadvantage and discrimination on children's futures. This contrasts, for example, with Titterton and Taylor's (2018: 1551) suggestion that 'disability, racism and lack of or poor attachment' are 'characteristics of the child, their family circle and wider community, which might threaten healthy development'; we argue that disability discrimination and racism are antecedent adversities generated in the past and now entrenched in broad patterns of belief, discourse and distributions of resources. This also extends Ungar's (2011) emphasis on variance in resilience; we argue the need to unpick patterns of consistency in the distribution of relevant conversion factors and to understand their historical roots.

We suggest that social work with children, young people and families could focus on the valued functioning of 'making a difference'. This takes forward calls for social work that confronts neoliberalism (Garrett, 2014, Featherstone et al, 2018) but avoids Garret's pessimism, recognising that spaces of ambiguity in existing social work practice can be used to name and address macro concerns (Houston, 2014, Roets and Roose, 2014). There may be scepticism that the weight interviewees placed on 'making a difference' arose from their exposure to dominant narratives (valuing volunteering and active citizenship) or engagement in participation activities that has pushed them into neoliberal self-governance, learning to fit in with current structures and inequalities (Raby, 2014). However, their focus was on working in partnership to name and change things for the better, not just having a say or taking part. Radical social work might therefore again be inspired by Freirean forms of participatory action (for example, Rogowski, 1995, Larkins, 2016) and, for example, the Black Lives Matter movement; these are 'making a difference' activities that focus on bringing about change through critical reflection and action, raising consciousness about barriers and continuing action to achieve change. It must involve linking children and young people's concerns to wider policy decisions and mechanisms in order to hold political decision-making to account (for example, Larkins, 2011; Kiili and Larkins, 2018).

Temporal and CA-inspired radical social work practice can use practice tools to disrupt enduring patterns of disadvantage interventions by strengthening a focus on ending disadvantage at a macro scale (discrimination based on gender, race and disability; funding and service decisions based on fixed conceptions of generation or prioritising national debt reduction; and lack of suitable employment).A first practice tool to bring into any existing approach to assessment and interventions might be critical questions to use in dialogue with children, young people and families: 
- What are the means and conversion factors that are limiting the capabilities and functionings available to this child or young person?

- What are the historical practices and events that have brought about these current personal, familial, social, economic, political and environmental conditions?

- Who can we collaborate with to overcome the historical events and practices that have brought about these barriers and the current actions that perpetuate them?

- How can children and young people experiencing these conditions be at the heart of investigating these questions and directing any future actions?

- How can we secure any gains in personal means or social and environmental conversion factors and ensure that these are sustained?

This is not simply about voice, tinkering in practice or co-producing research (Aranda and Hart, 2015; Hart et al, 2016), though these strategies are useful. It is about engaging in action in partnership with individuals and groups of children, young people and families. It involves political activism and campaigning to address root causes. It also involves continuing this struggle until changes are achieved and maintained.

A second practice tool might involve sharing and testing successful strategies for refocusing direct work on contexts rather than individual children, young people or families. Naming race and racism is suggested as a vital strategy in work with young people in contact with youth offending teams (Wainwright and Larkins, 2020) and may be equally important in work with children in contact with social services. Supporting disabled young people to gain employment can involve addressing external conversion factors (related to labour markets and social norms and practices) as these impede the capacity for young people to gain employment that they value (Egdell and McQuaid, 2016). Practice with looked-after children might therefore involve sharing with children what we know about the structural nature of stigma and historic patterns of social disadvantage (Morris et al, 2017; Tobis, 2013), and political education and activity (Moran-Ellis and Sünker, 2018). In the context of 'jobs being rarer than hen's teeth', letting looked-after children and young people know that the challenges to gaining employment relate to long-standing national and international decision-making about levels of regulation and expectation placed on employers as much as CVs might benefit young people's self-esteem.

\section{Conclusions}

Children and young people are knowledgeable partners in research and struggles for social justice. Ascribing responsibility to individuals, families or communities for the social circumstances in which they find themselves must be resisted. To transform these conditions, we need to hold to account past and present relevant governments and economic interests that affect living conditions. Within social work investigations and interventions, this involves naming and addressing the historical causal roots of social and economic inequalities, and recognising the extent to which socioeconomic deprivation, discrimination and inadequate funding for public services limit individuals' opportunities to convert their means into the functionings that they value. Our research shows how critical inquiry in collaboration with services users can to look back in time to generate greater understanding and work forward towards sustainable brighter futures. 
More research is needed to evaluate in what circumstances social work practice, in partnership with disadvantaged children, young people and families, can remove enduring inequalities, as well as overcome adversities. This suggestion is not new (Rogowski, 1995), but action to refocus social work with children in this direction is long overdue. By engaging with CA and extending socio-ecological resilience theory to embrace a critical realist understanding of agency and structure across time (Oliver 2012), this article strengthens the theoretical underpinning of this call to action.A first step would be for social work training and practice to turn away from investigation and towards co-creating activities to understand and challenge the roots, symptoms and consequences of oppression.

\section{Funding}

This work was supported by the UK Arts and Humanities Research Council under Grant AHM001539/1.

\section{Acknowledgements}

The authors wish to thank UCan, who initiated this research study, the young researchers, children and young people who took part, and the professionals who supported their participation. Thanks also to the anonymous reviews and to Kate Dumbleton for comments on an earlier draft of this article.

\section{Conflict of interest}

The authors declare that there is no conflict of interest.

\section{References}

Aranda, K. and Hart, A. (2015) Resilient moves: tinkering with practice theory to generate new ways of thinking about using resilience, Health, 19(4): 355-71.

Biggeri, M., Libanora, R., Mariani, S. and Menchini,L. (2006) Children conceptualizing their capabilities: results of a survey conducted during the first Children's World Congress on Child Labour, Journal of Human Development, 7(1): 59-83.

Bronfenbrenner, U. (1994) Ecological models of human development, International Encyclopaedia of Education, 3(2): 37-43.

Brownlie, J. (2009) Researching, not playing, in the public sphere, Sociology, 43(4): 699-716.

Burchardt, T. andVizard, P. (2011) Operationalizing the capability approach as a basis for equality and human rights monitoring in twenty-first-century Britain, Journal of Human Development and Capabilities, 12(1): 91-119.

Carpenter, M. (2009) The capabilities approach and critical social policy:lessons from the majority world?, Critical Social Policy, 29(3): 351-73.

Dan, D., Evie, O., Thomas, D. and Larkins, C. (2019) Next steps in children and young people's research, participation and protection from the perspective of young researchers, Journal of Children's Services, 14(3): 186-93.

Daniel, B. (2006) Operationalizing the concept of resilience in child neglect: case study research, Child: Care, Health and Development, 32(3): 303-9.

Daniel, B. (2010) Concepts of adversity, risk, vulnerability and resilience: a discussion in the context of the 'child protection system', Social Policy \& Society, 9(2): 231-41.

Daniel, B. and Wassell, S. (2002) Adolescence: Assessing and Promoting Resilience in Vulnerable Children, London: Jessica Kingsley. 
Dean, H. (2009) Critiquing capabilities: the distractions of a beguiling concept, Critical Social Policy, 29(2): 261-78.

Del Moral-Espin, L., Pérez-García,A. and Gálvez-Muñoz, L. (2017) Una buena vida. Definiendo las capacidades relevantes para el bienestar desde las voces de niñas y niños, Sociedad e Infancias 1: 203-37.

Donati, P. (2016) The 'relational subject' according to a critical realist relational sociology, Journal of Critical Realism, 154: 352-75.

Egdell,V. and McQuaid, R. (2016) Supporting disadvantaged young people into work: insights from the capability approach, Social Policy \& Administration, 50(1): 1-18.

Fattore,T. and Fegter, S. (2019) Children, social class and social practices:A theoretical analysis of children's practices of class distinction, Children and Youth Services Review, 97: 67-75.

Featherstone, B., Gupta,A., Morris, K. and White, S. (2018) Protecting Children:A Social Model, Bristol: Policy Press.

Felitti,V.J., Anda, R F., Nordenberg, D., Williamson, D.F., Spitz, A.M., Edwards,V. and Marks, J.S. (1998) Relationship of childhood abuse and household dysfunction to many of the leading causes of death in adults: The Adverse Childhood Experiences (ACE) Study, American Journal of Preventive Medicine, 14(4): 245-58.

Fraser, H. (2004) Doing narrative research: analysing personal stories line by line, Qualitative Social Work, 3(2): 179-201.

Fraser, N., Bhattacharya, T. and Arruzza, C. (2018) Notes for a feminist manifesto, New Left Review, 114(Nov-Dec): 113-34.

Garrett, P.M. (2014) Children and Families, Bristol: Policy Press.

Garrett, P.M. (2015) Questioning tales of'ordinary magic': 'resilience' and neo-liberal reasoning, British Journal of Social Work, 46(7): 1909-25.

Gupta,A., Featherstone, B. and White, S. (2016) Reclaiming humanity: from capacities to capabilities in understanding parenting in adversity, The British Journal of Social Work, 46(2): 339-54.

Hart,A., Gagnon, E., Eryigit-Madzwamuse, S., Cameron, J.,Aranda, K., Rathbone,A., and Heaver, B. (2016) Uniting resilience research and practice with an inequalities approach, Sage Open, 6(4): 1-13.

Houston, S. (2014) Social work and the sociological imagination, in P.M. Garret (ed) Children and Families, Bristol: Policy Press.

Joseph, J. (2016) Governing through failure and denial: the new resilience agenda, Millennium, 44(3): 370-90.

Kiili, J. and Larkins, C. (2018) Invited to labour or participate: intra- and intergenerational distinctions and the role of capital in children's invited participation, Discourse: Studies in the Cultural Politics of Education, 39(3): 408-21.

Larkins, C. (2011) Can the EU live up to the expectations of its child citizens?, International Journal of Children's Rights, 19(3:'Special Issue: Children and the European Union'): 451-76.

Larkins, C. (2016) Making the critical links: strategies for connecting marginalised children's action research with European citizenship, Social Work Review, XV(2), www.swreview.ro

Larkins, C. (2019) Excursions as corporate agents: a critical realist account of children's agency, Childhood, 26(4): 414-29.

Mass, W. and Lazonick, W. (1990) The British cotton industry and international competitive advantage: the state of the debates, Business History, 32(4): 9-65. 
Moran-Ellis, J. and Sünker, H. (2018) Childhood studies, children's politics and participation: perspectives for processes of democratisation, International Review of Sociology, 28(2): 277-97.

Morris, K., Mason, W., Bywaters, P., Daniel, B., Featherstone, B., Mirza, N., Brady, G., Bunting, L., Scourfield,J.B., Hooper,J. and Webb, C. (2018) Social work, deprivation and child welfare interventions, Child and Family Social Work, 23(3): 364-72.

Neocleous, M. (2013) Resisting resilience, Radical Philosophy, 178(March/April):2-7. Norman, P.D. (2016) The changing geography of deprivation in Britain, 1971 to 2011 and beyond, in T. Champion and J. Falkingham (eds) Population Change in the United Kingdom, London: Rowman \& Littlefield.

Nussbaum, M. (2011) Creating Capabilities: The Human Development Approach, Cambridge, MA: Harvard University Press.

Office for National Statistics (2017) Measures from the Adult Social Care Outcomes Framework, England - 2016-17, https://digital.nhs.uk/data-and-information/ publications/statistical/adult-social-care-outcomes-framework-ascof/archive/ measures-from-the-adult-social-care-outcomes-framework-england---2016-17

Oliver, C. (2012) Critical realist grounded theory: a new approach for social work research, British Journal of Social Work, 42(2): 371-87.

Parton, N. (2014) The Politics of Child Protection, Basingstoke: Palgrave Macmillan.

Raby, R. (2014) Children's participation as neo-liberal governance? Discourse: Studies in the Cultural, Politics of Education, 35(1): 77-89.

Roets, G. and Roose, R. (2014) Lost in Arcadia, in P.M. Garret (ed) Children and Families, Bristol: Policy Press.

Rogowski, S. (1995) Youth crime and community based initiatives: a critical look at their development and some thoughts on a radical practice, Practice: Social Work in Action, 7(4): 43-52.

Roose, R., Roets, G. and Schiettecat,T. (2014) Implementing a strengths perspective in child welfare and protection: a challenge not to be taken lightly, European Journal of Social Work, 17(1): 3-17.

Satchwell, C., Larkins, C., Carter, B. and Davidge, G. (2020) Making meaning through fictional writing with disadvantaged young people: stories as findings in collaborative research data analysis, Qualitative Research, (February 2020), doi: 10.1177/1468794120904892.

Sen, A. (1999) Development as Freedom, Oxford: Oxford University Press.

Sen, A. (2005) Human rights and capabilities, Journal of Human Development, 6(2): 151-66.

Sen, A. (2009) The Idea of Justice, London: Allen Lane.

Skattebol, J. and Redmond, G. (2019) Troubled kids? Locational disadvantage, opportunity structures and social exclusion, Children's Geographies, 17(1): 76-89.

Stevens, C., Proctor, F., Rishworth, B., Boorman, A., Unwin, A., Featherstone, B. and Bilson,A. (2019) Rethinking child protection and adoption: achieving social justice in practice, Critical and Radical Social Work, 8(1): 125-32.

Stoecklin, D. and Bonvin, J.M. (2014) Children's Rights and the Capability Approach, Dordrecht: Springer.

Titterton, M. and Taylor, J. (2018) Rethinking risk and resilience in childhood and child maltreatment, The British Journal of Social Work, 48(6): 1541-58.

Tobis, D. (2013) From Pariahs to Partners: How Parents and their Allies Changed New York City's Child Welfare System, New York: Oxford University Press. 
Ungar, M. (2011) The social ecology of resilience: addressing contextual and cultural ambiguity of a nascent construct, American Journal of Orthopsychiatry, 81(1): 1-17.

Ungar, M., Liebenberg, L. and Ikeda, J. (2014) Young people with complex needs: designing coordinated interventions to promote resilience, British Journal of Social Work, 44(3): 675-93.

Van Breda,A.D. (2018) Reclaiming resilience for social work: a reply to Garrett, The British Journal of Social Work, 49(1): 272-6.

Van Raemdonck, L. and Seedat-Khan, M. (2018) A case study on a generalist service delivery model for street children in Durban, South Africa: Insights from the capability approach, Child E Family Social Work, 23(2): 297-306.

Wainwright, J. and Larkins, C. (2020) Race, ethnicity, young people and offending: the elephant in the room, Social Identities, 26(1): 128-44.

Zabern, A. and Bouteyre, E. (2018) Leading protective factors for children living out of home: a literature review, Child \& Family Social Work, 23(2): 324-35.

Zolkoski, S.M. and Bullock, L.M. (2012) Resilience in children and youth: a review, Children and Youth Services Review, 34(12): 2295-303. 